Hydrol. Earth Syst. Sci. Discuss., https://doi.org/10.5194/hess-2017-662

Manuscript under review for journal Hydrol. Earth Syst. Sci.

Discussion started: 22 December 2017

\title{
Should radar precipitation depend on incident air temperature? A new estimation algorithm for cold climates.
}

\author{
Kuganesan Sivasubramaniam ${ }^{1}$, Ashish Sharma ${ }^{2}$, and Knut Alfredsen ${ }^{1}$ \\ ${ }^{1}$ Department of Civil and Environmental Engineering, Norwegian University of Science and Technology, 7491 Trondheim, \\ Norway \\ ${ }^{2}$ School of Civil and Environmental Engineering, University of New South Wales, Sydney, NSW2052, Australia \\ Correspondence to: Kuganesan Sivasubramaniam (kuganesan.sivasubramaniam@ntnu.no)
}

\begin{abstract}
In cold climates, the form of precipitation (snow or rain or mixture of snow and rain) results in uncertainty in radar precipitation estimation. Estimation often proceeds without distinguishing the state of precipitation which can be reliably specified as a function of associated air temperature. In the present study, we hypothesise that incident air temperature is related to the phase of the precipitation and ensuing reflectivity measurement, and therefore could be used in prediction models

5 to improve radar precipitation estimates in cold climates. This is the first study to our knowledge that assesses the dependence of radar precipitation on incident air temperature and presents a procedure that can be used for taking it into consideration. We use a data based nonparametric statistical approach for this assessment. A nonparametric predictive model is constructed with radar rain rate and air temperature as predictor variables and gauge precipitation as observed response using a k-nearest neighbour (k-nn) regression estimator. A partial information theoretic technique is used to ascertain the relative importance of the two predictors. Six years (2011-2017) of hourly radar rain rate from the Norwegian national radar network over the Oslo region, hourly gauged precipitation from 88 raingauges and gridded observational air temperature were used to formulate the predictive model and hence evaluate our hypothesis. The predictive model with temperature as an additional covariate reduces root mean squared error (RMSE) up to $15 \%$ compared to the predictive model with radar rain rate as the sole predictor. More than $80 \%$ of the raingauge locations in the study area showed improvement with the new method. Further, the estimated partial weight for air temperature assumed a zero value for more than $85 \%$ of gauge locations when temperature was above $10^{\circ} \mathrm{C}$, which indicates that the partial dependence of precipitation on air temperature is most important for colder climates.
\end{abstract}

\section{Introduction}

Hydrological applications require accurate precipitation estimates on the catchment scale. Precipitation is a spatio-temporal process and traditionally used raingauges are often inadequate as they represent point measurements and necessitate a dense network to capture the spatial variation (Beven, 2012; Kirchner, 2009). Weather radars provide quantitative precipitation estimates over a large area with high spatial and temporal resolution. However, weather radars measure the rain rate indirectly, using the energy scattered back by hydrometeors in the volume illuminated by a transmitted electromagnetic beam (Villarini and Krajewski, 2010b). The backscattered energy is termed as reflectivity and used as the basis to quantify the associated precipitation. This measured reflectivity depends on many factors such as size, shape, orientation (if non-spherical), state and 
Hydrol. Earth Syst. Sci. Discuss., https://doi.org/10.5194/hess-2017-662

Manuscript under review for journal Hydrol. Earth Syst. Sci.

Discussion started: 22 December 2017

(C) Author(s) 2017. CC BY 4.0 License.
Hydrology and

Earth System

Sciences

Discussions

(c) (i)

concentration of particles in the radar illuminated volume in the atmosphere along with their dielectric properties (Hong and Gourley, 2015; Joss et al., 1990).

The nature of radar precipitation measurements is subject to many sources of error. These errors occur during the sampling or measurement of reflectivity as well as in the process of converting the reflectivity to rain rates (Chumchean et al., 2006). Due to the presence of such significant errors (both random and systematic), radar data are still not used in hydrological applications as broadly and efficiently as they could be (Berne and Krajewski, 2013; Chumchean et al., 2003). Many studies (e.g., Abdella, 2016; Villarini et al., 2008; Ciach et al., 2007; Chumchean et al., 2006) have focused on estimating these uncertainties for quantitative radar precipitation estimates; however, some of the underlying physical processes are still not understood well enough to allow significant advances being made (Villarini and Krajewski, 2010a). The scope of the present study is limited to radar precipitation estimation uncertainty during conversion from reflectivity to rain rate, with a focus on cold regions experiencing a mixture of solid and liquid precipitation.

Conventionally, radar measurements of reflectivity $(Z)$ are converted into rain rate $(R)$ using the parametric $Z-R$ relationship derived by Marshall and Palmer (1948) in the form of a power law, $Z=a R^{b}$. The variability of the power law parameters is related to a number of factors including the drop size distribution (DSD) of hydrometeors. Drop size distribution varies with time and space as well as with type and phase of precipitation (Chumchean et al., 2008; Joss et al., 1990; Uijlenhoet, 2001). Therefore, the Z-R relationship is not unique and hence, we depend on empirical relationships instead (Wilson and Brandes, 1979). Nevertheless, weather radar operations in cold climates are generally calibrated to measure the water equivalent radar reflectivity factor (dielectric constant for water is used) and it is converted to rain rate by using a single Z-R relation for radar rainfall throughout the year (Koistinen et al., 2004). However, use of the single reflectivity-precipitation relationship could bring phase dependent bias in radar precipitation estimation.

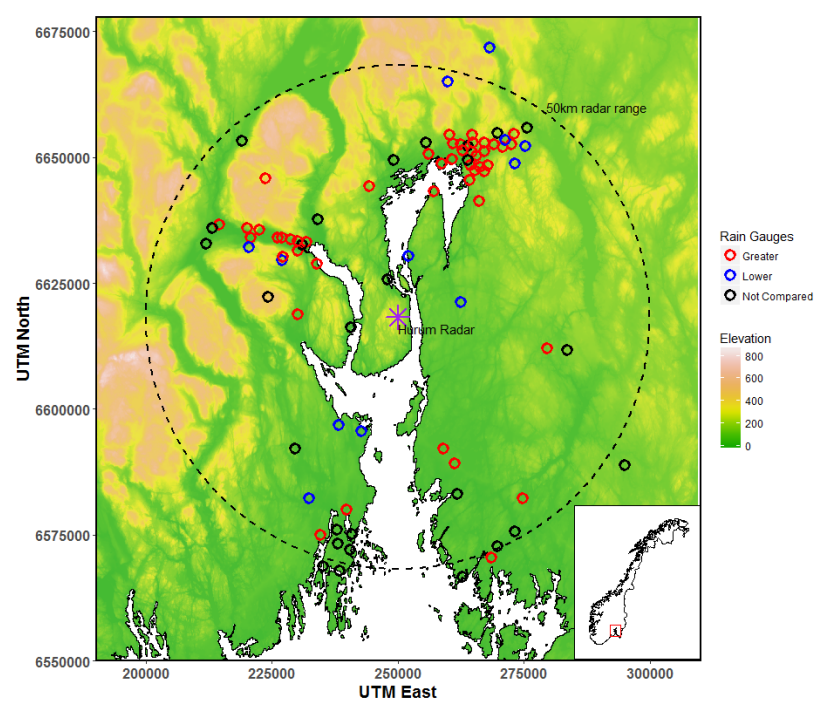

Figure 1. Comparison of regression slope for snow and rain data pairs of gauging stations overlaid on topography of the study area. 
Hydrol. Earth Syst. Sci. Discuss., https://doi.org/10.5194/hess-2017-662

Manuscript under review for journal Hydrol. Earth Syst. Sci.

Discussion started: 22 December 2017

(c) Author(s) 2017. CC BY 4.0 License.

Given the use of weather radars to estimate rainfall across a wide range of climates, the focus of this study is whether the estimation procedures used need to be cognizant of the incident air temperature, as little consideration is currently given on whether the rainfall represents solid or liquid precipitation droplets. Consider the results in Fig. 1 which shows a simple linear regression analysis of observed hourly pairs of gauge precipitation and radar rain rate measurement at those raingauges' locations in the Oslo region of Norway. Based on the air temperature at the gauge location, data pairs were simplistically classified as rain (temperature greater than $+6^{\circ} \mathrm{C}$ ) or snow (temperature less than $-2^{\circ} \mathrm{C}$ ). The linear regression slope for both rain and snow data pairs were computed for each gauge location and compared. In Fig. 1, the raingauge locations with a greater regression slope for rain than snow are displayed with red open circles and a lower regression slope with blue. Gauges with few available snow pairs (less than $5 \%$ of the maximum snow pairs) were excluded from comparison and are shown with black open circles. The regression slope for rain pairs is greater than regression slope of snow for $80 \%$ of the gauges under comparison. We hypothesise that this is a result of the bias in the radar precipitation estimation for snow because no explicit parameterisation for the effect of temperature is considered in the Z-R relationship. This finding, while preliminary, laid the motivation for this study. This result is consistent with that of Wright et al. (2014) over the southeastern region of the USA, who also reported that the correlation is generally higher for the warm season than for the cold season for all accumulation periods of rainfall.

To date, less attention is paid to snow than rain in the context of quantitative radar precipitation estimation (Berne and Krajewski, 2013). In many studies, radar precipitation estimates are limited to summer months and or snowfall periods are either not mentioned or excluded (Saltikoff et al., 2015). However, accurate quantitative precipitation (snow or mixture of snow and rain) measurements during the cold winter are also required for operational hydrological applications (hydropower production planning, water management and snowmelt flood protection), aviation and road traffic management and data assimilation in Numerical Weather Prediction (NWP) models (Gjertsen and Ødegaard, 2005; Saltikoff et al., 2015). Further, a continuous time series of radar based precipitation estimates and the reduced reliance on traditional raingauges are of great interest to hydrologists. If a continuous time series is to be generated from weather radars in boreal regions, the effect of snow or varying precipitation phase on radar precipitation estimates must be studied in detail.

Starting from its origin and throughout its entire journey, the rain drop is shaped by temperature. During the formation and growth of cloud droplets, different temperatures cause different shapes of crystals to form, and then the crystals start to fall. The falling crystals are then characterised by the temperature of the air through which they fall. So, the air temperature determines the final properties and the phase of the hydrometeor that reaches the ground surface (Fassnacht et al., 2001). Further, studies showed that there are multiple snow types which vary with time, partially due to temperature (Saltikoff et al., 2015). Many studies (Auer Jr, 1974; Kienzle, 2008; Killingtveit, 1976; Rohrer, 1989) examined the relationship between the occurrence of the precipitation phases (snow, rain and mixture of snow and rain) and temperature. The probability of occurrence of snowfall versus temperature shows an approximately ' $S$ ' shaped structure in these studies. Additionally, as mentioned earlier, measured reflectivity depends on dielectric properties of hydrometeors. The dielectric property of solid particles (ice) is very different from liquid particles (water) and moreover, it varies with temperature (Joss et al., 1990). These imply that temperature is intrinsic to both the phase of precipitation and the ensuing reflectivity measurement. 
Hydrol. Earth Syst. Sci. Discuss., https://doi.org/10.5194/hess-2017-662

Manuscript under review for journal Hydrol. Earth Syst. Sci.

Discussion started: 22 December 2017

(c) Author(s) 2017. CC BY 4.0 License.

In this study, we hypothesise that observed air temperature can be used in prediction models to improve radar precipitation estimates in cold climates. High resolution (hourly or sub hourly) observations of incident air temperature and gauge rainfall are available with good quality at many locations around the world, making it possible to test our hypothesis. The data based investigation here uses nonparametric statistical techniques, which are applicable where the underlying model is not known (Sharma and Mehrotra, 2014). The partial informational correlation and partial weight framework in Sharma and Mehrotra (2014) enables assessment of the link between radar precipitation and ground precipitation and air temperature, allowing a data based relationship to be formed.

The rest of the paper is structured as follows. The following section reviews the radar precipitation estimation in cold climates as well as nonparametric methods for radar rainfall estimation. The methods and tools used to set up a prediction model based on our proposed hypothesis are presented in Section 3. Section 4 describes the study area and data used to test the method. The results obtained from the study are discussed in Section 5. Finally, summary and conclusions are presented in Section 6.

\section{Background}

\subsection{Radar precipitation estimates in cold climates}

In cold climates, precipitation is in the form of snow or rain or mixture of snow and rain. Theoretically, radar reflectivity measurement of rainfall and snowfall do not differ much. The requirement (particles small enough to fall in the Rayleigh scattering region) for raindrops can also be valid for snowflakes and small ice particles (Marshall and Gunn, 1952; Smith, 1984). For the case of snowfall, the dielectric constant of the liquid phase is replaced by the dielectric constant of the solid phase of the precipitation (Smith, 1984). However, unlike raindrops, snowflakes do not have clear shape and moreover, their composition (proportions of solid, liquid and gas) is not unique (Berne and Krajewski, 2013; Chandrasekar et al., 2013). The varying composition greatly influences the scattering properties of snowflakes. As a result, uncertainties in quantitative radar snowfall estimation is much higher than the radar rainfall estimation (Berne and Krajewski, 2013).

Since Marshall and Palmer (1948) derived the empirical radar reflectivity-rainfall relationship in the form of a power law, subsequent research focus was to refine the relationship for radar snowfall estimates (Fassnacht et al., 2001). Several studies (Battan, 1973; Marshall and Gunn, 1952; Sekhon and Srivastava, 1970) investigated and then proposed different possible parameter set ( $\mathrm{a}$ and $\mathrm{b}$ in the power law relationship, $Z=a R^{b}$ ) for snow. The parameter set proposed by Sekhon and Srivastava (1970) has been used as a standard for snow as like Marshall and Palmer (1948) for rain (Fassnacht et al., 2001; Saltikoff et al., 2015). Some of the radar operations in cold climates (e.g., Finland and Canada) uses these two sets of parameters for rain and snow (Koistinen et al., 2004). However, Saltikoff et al. (2000) reported that real time phase dependent adjustment of two different parameter sets does not improve the snowfall estimates significantly. To account for varying precipitation phase (multiple snow types and mixture of snow and rain), many parameter sets could be required. Moreover, precipitation phase changes rapidly even within the single snow storm and hence, operationally, switching between different parameter sets is a challenging task (Koistinen et al., 2004; Saltikoff et al., 2015). 
Hydrol. Earth Syst. Sci. Discuss., https://doi.org/10.5194/hess-2017-662

Manuscript under review for journal Hydrol. Earth Syst. Sci.

Discussion started: 22 December 2017

(c) Author(s) 2017. CC BY 4.0 License.

For the use of phase dependent reflectivity-precipitation (Z-R) relationship, the precipitation phase of the radar pixel must be estimated. As mentioned in the introduction, air temperature is used to determine the phase (whether snow or rain) of the precipitation. The Finnish meteorological institute operationally uses temperature and humidity observations from synoptic stations to estimate the precipitation phase and use that information to use a different parameter set for rain or snow (Koistinen

5 et al., 2004). Fassnacht et al. (2001) demonstrate the use of surface air temperature to estimate the fraction of snow content in mixed precipitation and use it to adjust radar estimate for mixed precipitation. They reported that the adjustment improved the accumulated snow estimates in Ontario, Canada. The focus of these studies is to use the temperature to differentiate the precipitation phases. Meantime, Observations from dual polarised weather radars can be used to classify precipitation phases (Ryzhkov and Zrnic, 1998). Operational use of dual polarised radars in hydrometeor classification has progressed significantly; however, the classification for high latitude winter storms is still challenging (Chandrasekar et al., 2013).

\subsection{Nonparametric Radar rainfall estimates}

When sufficient data are available, nonparametric approaches are efficient alternatives for specifying an underlying model as compared to parametric (or regression type) approaches. Nearest neighbour resampling and kernel density estimation are amongst the most commonly used nonparametric methods. The simplicity of nonparametric approaches have made them attractive for use in hydrology and other sciences (Mehrotra and Sharma, 2006). A key advantage of nonparametric approaches is that less rigid assumptions about the distribution of the observed data (Silverman, 1986) and hence no major assumptions about the process being modelled to construct the complete predictive system (Sharma and Mehrotra, 2014). Due to the availability of enough radar rain rate observations and the need for the less assumptions about the underlying physical process, nonparametric methods could be more appropriate for radar precipitation estimates.

Ciach et al. (2007) used the nonparametric kernel regression to model radar rainfall uncertainty. They described the relation between true rainfall and radar-rainfall as the product of a systematic distortion function and a random component, and procedures presented to identify the two components. The distortion function can account for systematic biases which can be mathematically defined as a conditional expectation function and the random component accounts for random errors in radar rainfall estimation. Villarini et al. (2008) estimated the conditional expectation function (distortion function) using both nonparametric (similar to Ciach et al. (2007)) and parametric (copula based) methods and they compared the performance between the two approaches by using different quality metrics. It was found that performance of the nonparametric method is comparable with copula-regression estimate and even outperformed when Nash Sutcliffe Efficiency (NSE) was used as a quality metric. The strength of nonparametric method is the ability to adapt to the data locally and the weakness is that the method is sensitive to outliers and to large variability of data at the smallest (sub hourly) time scales. Hasan et al. (2016b) presented a kernel based nonparametric method for radar rainfall estimation. In their approach, expected ground rainfall is estimated for a given reflectivity by using a kernel based conditional probability distribution. However, none of the methods above consider an additional covariate as proposed in the present study. 
Hydrol. Earth Syst. Sci. Discuss., https://doi.org/10.5194/hess-2017-662

Manuscript under review for journal Hydrol. Earth Syst. Sci.

Discussion started: 22 December 2017

\section{Methodology}

This section describes the methods used to formulate a nonparametric predictive model with incident air temperature and radar rain rate as the two predictors for radar precipitation in cold climates. A description of how the incident air temperature is incorporated as a covariate in the nonparametric radar precipitation estimation approach is presented next.

\section{$5 \quad 3.1 \quad$ Radar precipitation estimation}

The radar precipitation prediction consists of two steps. The first step quantifies the partial dependence of precipitation on radar rain rate and incident air temperature. The second step then uses the identified predictors in a non-parametric setting to estimate the precipitation response. Gauge precipitation is used as a ground reference or true precipitation in this study.

The conditional estimation of precipitation using the two covariates can be described as follows:

$10 R_{e s t}(t) \mid[R(t), T(t)]$

Here, $\left(R_{e s t}(t)\right)$ is the estimated ground precipitation from a given pair of radar rain rate $(R(t))$ and incident air temperature $(T(t))$ at a given location and time, $t$.

Equation 1 can be used to ascertain the conditional expectation of radar rainfall using two covariates. An example of a conditional expectation estimate of radar rainfall with a single covariate (radar reflectivity) using kernel regression is provided in (Hasan et al., 2016a, b). Readers are referred to (Mehrotra and Sharma, 2006; Sharma and Mehrotra, 2014; Sharma et al., 2016) for further details on the nonparametric modelling framework used in this work. This study uses the k-nearest neighbour $(\mathrm{k}-\mathrm{nn})$ regression estimator as the nonparametric predictive model. This model can be expressed as:

$$
E\left(R_{\text {est }}(t) \mid[R(t), T(t)]\right)=\sum_{k} \frac{\frac{g_{k}}{k}}{\sum_{j=1}^{K} \frac{1}{j}}
$$

Where $k$ denotes the number of past observed pairs of radar rain rate and air temperature whose distance from the conditioning vector $[R, T]$ is less than or equal to the distance to the $K^{t h}$ data point and $E($.$) denotes the expectation operator. Here, g_{k}$ is the observed gauge precipitation corresponding to $k^{\text {th }}$ neighbour of the conditioning vector. $K$ is a maximum number of neighbours permissible and it is an important parameter in the k-nearest neighbour method. In the present study, $K$ is taken as equal to the square root of the sample size as suggested by Lall and Sharma (1996).

The order of each neighbour is ascertained based on a weighted Euclidean distance metric, written as:

$25 \xi_{i}^{2}=\left(\frac{\beta_{R}\left(R-r_{i}\right)}{s_{R}}\right)^{2}+\left(\frac{\beta_{T}\left(T-t_{i}\right)}{s_{T}}\right)^{2}$

Here, $\xi_{i}$ is the distance of the conditioning vector $[R, T]$ to the $i^{\text {th }}$ data point $\left(r_{i}, t_{i}\right)$ in a two-dimensional space. $s_{R}$ and $s_{T}$ are sample standard deviations of radar rain rate and temperature, and $\beta_{R}$ and $\beta_{T}$ are partial weights denoting the relative impor- 
Hydrol. Earth Syst. Sci. Discuss., https://doi.org/10.5194/hess-2017-662

Manuscript under review for journal Hydrol. Earth Syst. Sci.

Discussion started: 22 December 2017

tance each conditioning variable has on the ensuing response respectively (Sharma and Mehrotra, 2014). The sample standard deviations are used to normalize the predictor variables and to make them independent of their measurement scale, while the partial weights allow elimination of a predictor variable if not relevant to the prediction being made. Readers are referred to Sharma and Mehrotra (2014) for the informational theory rationale that allows for the estimation of these partial weights, and

5 the NPRED, R package ((Sharma et al., 2016), downloadable from http://www.hydrology.unsw.edu.au/download/software/npred) that enables their estimation for any sample data set.

\subsection{Model evaluation criteria}

A different number of metrics are used in literature to evaluate and compare the performance of models (Hasan et al., 2016b; Villarini et al., 2008). We used root mean squared error (RMSE) as a quality metric to evaluate the performance of the precipitation prediction model. The RMSE is commonly used as a performance measure and it provides the overall skill measure of a predictive model (Hasan et al., 2016b). The RMSE estimates the residuals between the expected precipitation $\left(R_{e s t}\right)$ predicted from the model and the observed gauge precipitation $\left(G_{o b s}\right)$ as written below:

$R M S E=\sqrt{\frac{1}{n} \sum_{i=1}^{n}\left(R_{e s t}-G_{o b s}\right)^{2}}$

\section{Study area and data}

The proposed nonparametric predictive model with radar rain rate and temperature as covariates was tested on radar rain rate measurements over the Oslo region in Norway. The radar data used in this research is accumulated hourly radar rain rate product generated from the national weather radar network of Norway. The present study area is limited to the $50 \mathrm{~km}$ radius of radar range from Hurum radar station (shown in Fig. 1) where a relatively dense network of raingauges are available. The Hurum radar is located at $59.63^{\circ} \mathrm{N}$ latitude and $10.56^{\circ} \mathrm{E}$ longitude and it is about $30 \mathrm{~km}$ from Oslo, the capital city of Norway.

The Norwegian Meteorological Institute (met.no) operates nine C-band Doppler weather radar installations which covers the entire land surface of Norway. The sensitive C-band installations with smaller wavelengths $(4-8 \mathrm{~cm})$ are placed to detect snowfall and clear air echoes (Koistinen et al., 2004). The Norwegian radar network scans the atmosphere with 7.5 minutes temporal resolution. The met.no process the raw radar volume scan from the radar stations. The data goes through extensive quality control and data transformations before the radar products are distributed to end users (Elo, 2012). The met.no performs a routine that removes clutter and other noise (non-meteorological echo) from the radar scan first. Then it reconstructs the gap in the data caused by clutter. The processing algorithm segments the volumetric radar reflectivity data as convective or stratiform precipitation type and it computes the Vertical Profile of Reflectivity (VPR) depending on precipitation types. VPRs of convective and stratiform precipitation types are distinctly different shapes (Abdella, 2016). Bright band effect and nonuniform vertical profile of reflectivity are major sources of uncertainties in radar precipitation estimation in high latitude region 
Hydrol. Earth Syst. Sci. Discuss., https://doi.org/10.5194/hess-2017-662

Manuscript under review for journal Hydrol. Earth Syst. Sci.

Discussion started: 22 December 2017

(c) Author(s) 2017. CC BY 4.0 License.

(Abdella, 2016; Joss et al., 1990; Koistinen et al., 2004; Koistinen and Pohjola, 2014). The radar data is corrected for VPR that includes handling the bright band correction.

After the processing, the met.no generates and distributes various radar products. One of the radar rain rate product available for the public to use in hydrological applications is the Surface Rainfall Intensity (SRI). The SRI product uses the lowest Plan Position Indicator (PPI) and project the aloft reflectivity data down to a reference height (1 km) near to the ground. The projection method is known as VPR correction that takes the vertical variability of reflectivity and bright band effect into account (Elo, 2012). The VPR corrected reflectivity is transformed from polar to Cartesian coordinate system with $1 \mathrm{~km} \times 1 \mathrm{~km}$ spatial resolution and the mosaic of nine weather radar imageries is merged to single SRI product covering the entire Norway. Finally, the reflectivity is converted to rain rate by using parametric Z-R relationship $\left(Z=200 R^{1.6}\right)$ derived by Marshall and Palmer (1948) and the rain rate is accumulated to given temporal resolution (hourly in this case). It can be noted that there are no seasonal variations in the Z-R relationship in any of the Norwegian radars.

Data for the period from January 2011 to April 2017 were used for this study. A subset of accumulated hourly radar rain rate with $1 \mathrm{~km} \times 1 \mathrm{~km}$ spatial resolution for the study area was downloaded from the met.no's thredds server (http://thredds.met.no/). The data is in NetCDF file format and the gridded array is in Universal Transverse Mercator (UTM) 33 projected coordinate system. The hourly precipitation measurements from raingauges are downloaded from the met.no's web portal for accessing meteorological data for Norway, "eKlima" (http://eklima.met.no). Within the study region, there are 88 raingauges available with hourly precipitation measurements. The raingauges' locations are shown in Fig. 1 overlaid on the topography of the study area. Raingauges are not evenly distributed. The urban areas (Oslo, Drammen, Lillestrom and Tonsberg) are densely gauged and rest of the area is sparsely gauged with hourly observation. Further, the precipitation data from raingauges comes with varying length because some gauges are in operation since 2013 or later and some gauges have a number of missing values during their operation. However, we used all raingauge locations for this study. Some of the gauging stations are equipped with temperature and other meteorological measurements but not all. However, a gridded air temperature dataset with $1 \mathrm{~km} \times 1 \mathrm{~km}$ grid resolution is available from the Norwegian meteorological institute. This gridded dataset for Norway is spatially interpolated based on the historical air temperature observations from Norwegian meteorological stations (Lussana et al., 2016). The gridded temperature data with an hourly temporal resolution were used to derive temperature time series for the raingauge locations.

As raingauge locations and radar rain rate grids are in the same UTM33 coordinate system, they were simply overlaid and the radar pixel of $1 \mathrm{~km}^{2}$ overlapping each raingauge was located. Then, the pixel value (rain rate) for each hour was extracted and continuous hourly time series of radar rain rates for all gauges were generated. For the study period, the time series consists of 55488 hourly timestamps. Radar rain rates for 2656 timestamps are missing for the whole period and flagged as missing data. The precipitation intensities in the study area (high latitudes) is relatively low. An analysis of statistical properties of rain rates in mid Norway showed that intensities less than $1.76 \mathrm{~mm} \mathrm{~h}^{-1}$ contributes to $50 \%$ of the total precipitation volume while less than $6 \mathrm{~mm} \mathrm{~h}^{-1}$ contributes to $88 \%$ (Engeland et al., 2014). Further, it was found that precipitation intensities below $0.1 \mathrm{~mm} \mathrm{~h}^{-1}$ contributes little to the total precipitation and might be treated as zero precipitation. Timestamps with gauge precipitation or radar rain rate less than $0.05 \mathrm{~mm} \mathrm{~h}^{-1}$ were therefore removed in this study. Finally, an observed dataset of 
Hydrol. Earth Syst. Sci. Discuss., https://doi.org/10.5194/hess-2017-662

Manuscript under review for journal Hydrol. Earth Syst. Sci.

Discussion started: 22 December 2017

(c) Author(s) 2017. CC BY 4.0 License.

(c) (1)
Hydrology and

Earth System

Sciences

Discussions

hourly gauge precipitation and radar rain rate pairs and air temperature for those timestamps were prepared for all raingauge locations.

\section{Results}

For each raingauge location, we estimated the partial weights associated with radar rain rate and incident air temperature using

5 the observed pairs of hourly radar rain rate and air temperature and the corresponding gauge precipitation.

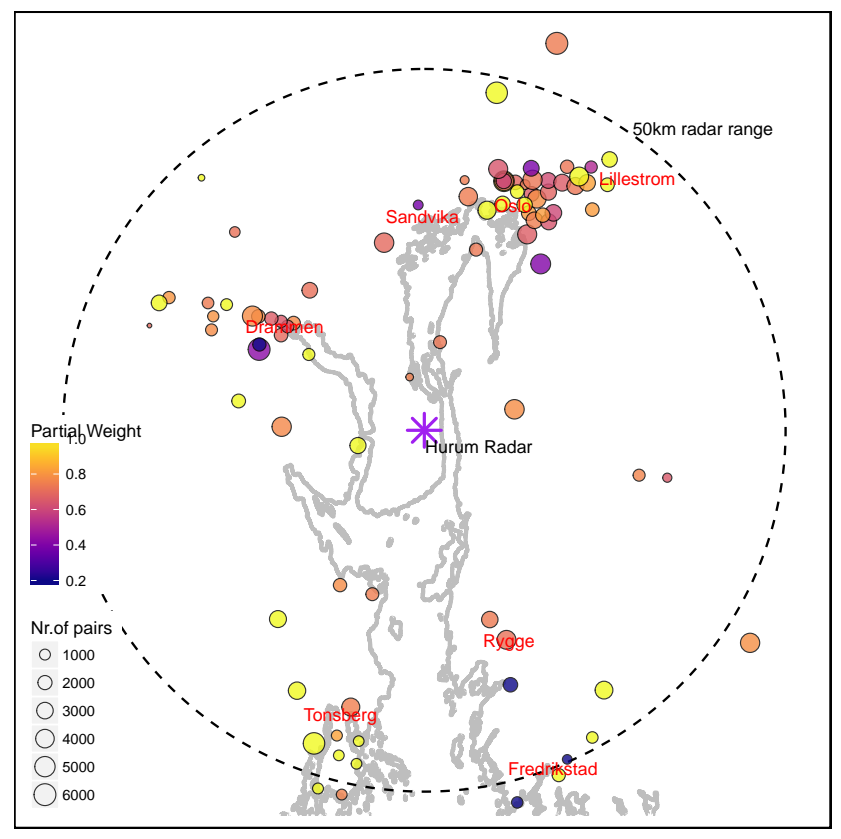

Figure 2. Partial weights of radar rain rate $\left(\beta_{R}\right)$ for raingauge locations (colour scale) and number of pairs (circle size) overlaid on the coastline of the study area.

Figure 2 shows the partial weight of radar rain rate $\left(\beta_{R}\right)$ computed for raingauge locations. The raingauges' locations are shown by circles and their sizes are proportional to the number of hourly timestamps of observed data used to estimate partial weights for those gauges' locations. As we mentioned earlier in section 4, radar rain rate and air temperature observations are mostly complete and the varying length of the data pairs is due to missing (or not in operation) gauge precipitation records. A filled colour scale is used to show the values of computed partial weights. It is noted that the summation of partial weights of radar rain rate $\left(\beta_{R}\right)$ and air temperature $\left(\beta_{T}\right)$ is scaled to 1 . Hence, the partial weight associated with air temperature $\left(\beta_{T}\right)$ is equal to $1-\beta_{R}$. Major cities in the study area are shown in the figure and used to describe details locally.

Nearly $70 \%$ of the raingauge locations were estimated with associated partial weight for air temperature. With reference to Fig. 2, the circles filled with brown tone colour are in the majority and they are dispersed throughout the study area. They represent the partial weight of radar rain rate in the range of between 0.6 and 0.8 and hence the partial weight of air temperature 
Hydrol. Earth Syst. Sci. Discuss., https://doi.org/10.5194/hess-2017-662

Table 1. Summary statistics of computed partial weights for radar rain rate and air temperature in the study area.

\begin{tabular}{lcccccc}
\hline Partial Weight & Mean & Median & 1st Quartile & 3rd Quartile & 15th Percentile & 70th Percentile \\
\hline Radar rain rate $\left(\beta_{R}\right)$ & 0.76 & 0.75 & 0.68 & 1.0 & 0.64 & 0.83 \\
Air temperature $\left(\beta_{T}\right)$ & 0.24 & 0.25 & 0.32 & 0.0 & 0.36 & 0.17 \\
\hline
\end{tabular}

is between 0.4 and 0.2 . It shows that radar precipitation estimation partially depends on air temperature in these locations. The yellow circles show gauge locations with the partial weight of radar rain rate $\left(\beta_{R}\right)$ equal to 1 and the partial weight associated with air temperature $\left(\beta_{T}\right)$ is therefore zero. There, the bivariate problem is collapsed into univariate problem with radar rain rate as a single predictor. With reference to Fig. 1, most of the locations of yellow filled circles in Fig. 2 coincide with gauge locations that consist of fewer snow data pairs. However, a few gauge locations with a sufficient number of data points and snow observations are also estimated with zero partial weight for air temperature.

Four raingauge locations (one in Drammen, two in Fredrikstad and one in Rygge) were computed with zero partial weight for radar rain rate and selected temperature as a single predictor. Those locations are displayed with dark blue colour circles. This outcome is a result of sampling uncertainty due to which a minimum of 0.2 for the partial weight for radar rain rate has been used in the results.

Table 1 shows the summary statistics of computed partial weights among the raingauge locations in the study area. It can be seen from the table that the mean is almost same as the median and the partial weight associated with air temperature is in the range of mean \pm 0.1 for $55 \%$ of gauge locations and it is $80 \%$ of which identified air temperature as an additional covariate.

The observed dataset and the computed partial weights of predictors were used with a k-nn regression estimator to setup predictive models for each gauge location. The k-nn estimator uses past observed hourly pairs of radar rain rate and air temperature as predictors and corresponding hourly gauge precipitation as an observed response to predict precipitation for a new pair of radar rain rate and air temperature. We calculated the expected response by leave-one-out cross-validation procedure, whereby leaving out one observed response value (gauge precipitation) from the regression and estimating the expected response. A vector of expected precipitation was estimated and the root mean square error (RMSE) was calculated for each gauge location from estimates and corresponding observed precipitation which was left out from the estimation.

To evaluate the improvement with the use of air temperature as an additional covariate, a predictive model with radar rain rate as a single predictor was used as a reference model. The reference model uses past observed hourly radar rain rate as a predictor and corresponding gauge precipitation as an observed response to predict the precipitation for a new radar rain rate observation. The RMSE was computed for the reference model and the reduction in RMSE was calculated. The improvement in radar precipitation estimation is measured as a percentage reduction in RMSE and shown in Fig. 3.

The improvement is up to $10-15 \%$ and those locations are shown with purple/dark blue colour circles. Further, they are dispersed in the study area except for the most southerly locations. Further, it can be noted that all the gauge locations with an associated partial weight of air temperature $\left(\beta_{T}>0\right)$ shows an improvement in radar precipitation estimation. Those four 
Hydrol. Earth Syst. Sci. Discuss., https://doi.org/10.5194/hess-2017-662

Manuscript under review for journal Hydrol. Earth Syst. Sci.

Discussion started: 22 December 2017

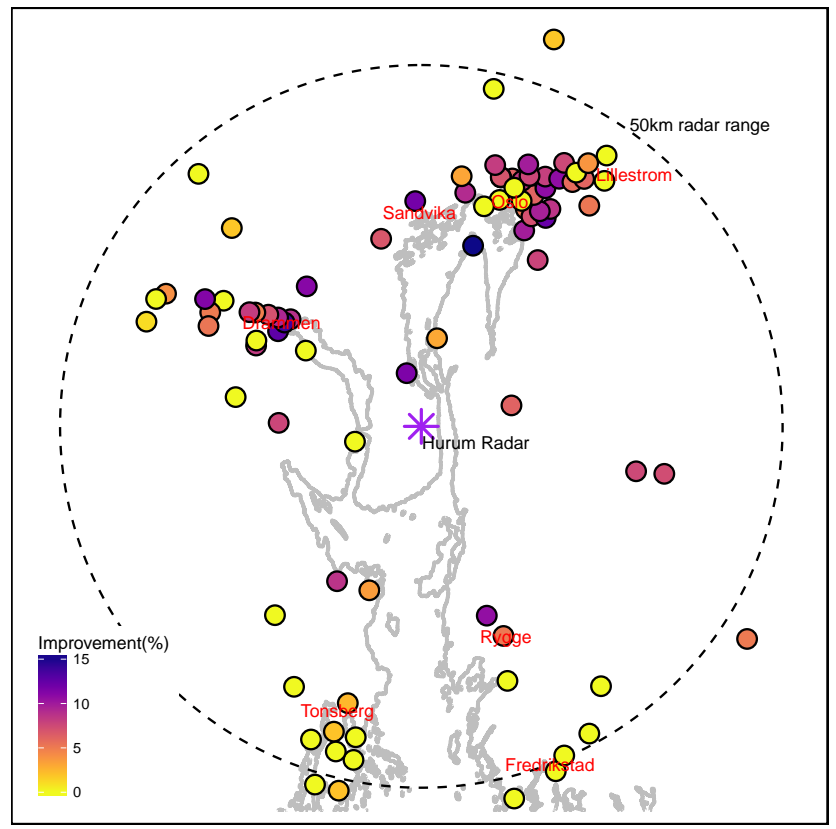

Figure 3. Percentage of improvement in RMSE by predictive model with radar rain rate and air temperature as the two predictors, compared to radar rain rate as a single predictor.

raingauge locations with a minimum partial weight for radar rain rate $\left(\beta_{R}=0.2 \& \beta_{T}=0.8\right)$, did not show improvement in RMSE.

An arithmetic mean value of the partial weights of raingauge locations was calculated for the study area. As shown in Table 1, the mean value of partial weight for radar rain rate is 0.76 and air temperature is 0.24 . The k-nn regression prediction model of each gauge location was tested with the average partial weight. Figure 4 shows the percentage improvement in RMSE compared to the predictive model with radar rain rate as a single predictor. Except for a few locations, all the raingauge locations show improvement in RMSE when using the mean value of the partial weight for the study area. Over $80 \%$ of the gauge locations in the study area show more than $3 \%$ improvement in RMSE while $33 \%$ (29 gauge locations) show more than $7.5 \%$ improvement and the maximum improvement is $14.3 \%$. It can be noted that gauge locations, which were computed with zero partial weight for air temperature, also showed improvement in RMSE with the mean partial weight. When the mean partial weight was assigned, three of those four anomalous gauge locations during the partial weight computation, also showed improvement in RMSE.

The raingauge locations with no improvement in RMSE which are shown with yellow circles in Fig. 4 are in Drammen (2 gauges), Tonsberg (2 gauges) and Fredrikstad (1 gauge). The dependency on air temperature could be lesser in these locations. However, the two raingauges in Drammen consists of the fewest data points for regression because of many missing values in the gauged precipitation series. As mentioned in section 3, this study uses the gauge precipitation as the observed response for 
Hydrol. Earth Syst. Sci. Discuss., https://doi.org/10.5194/hess-2017-662

Manuscript under review for journal Hydrol. Earth Syst. Sci.

Discussion started: 22 December 2017

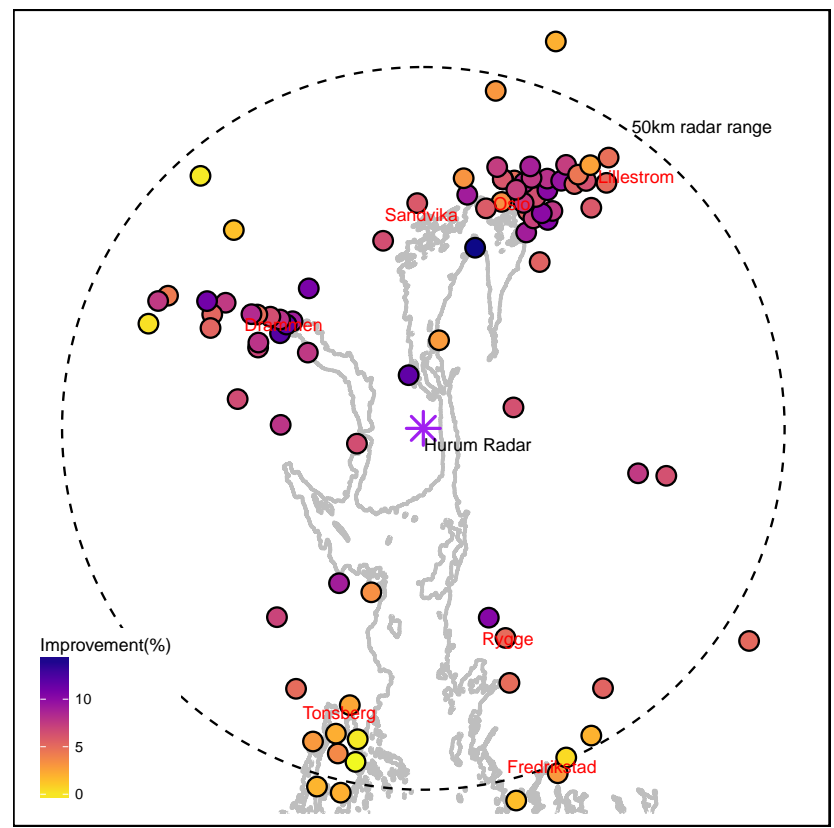

Figure 4. Percentage of improvement in RMSE when a single average partial weight is used for radar rain rate and air temperature, compared to radar rain rate as a single predictor.

the regression estimation. So insufficient data points can also be the reason for lesser improvement in these locations because nonparametric k-nearest neighbour prediction (a data based model) depends highly on the availability of sufficient data.

We examined the spatial cross-validation of computed partial weights. For each gauge location, average partial weight was calculated by leaving that gauge out and using the mean partial weight from five nearest gauges. The k-nn prediction model was set up for each gauge location with the computed average partial weight of 5 nearest gauges. Figure 5 shows the results of percentage improvement in RMSE. It can be seen that Fig. 5 shows a strong resemblance to the result presented in Fig. 4 with a single mean value of partial weight for the study area. It is possible, therefore, that a regional or nearest neighbour average value of partial weight can be used for any ungauged location.

It can be seen in Fig. 3 to 5, the raingauge locations in southerly locations (Tonsberg and Fredrikstad) show lesser improvement in RMSE for the predictive model with air temperature as an additional covariate. In southerly locations, raingauges are located on lower elevations and several are almost at sea level (less than $5 \mathrm{~m}$ above sea level). Moreover, the value of average negative air temperature is lower for these locations than the other locations used in the study. This can be a potential reason for lesser dependence on air temperature for these locations and hence the reduced improvement in RMSE.

Although the main focus of this study is to investigate the importance of temperature in radar precipitation estimation, the results of nonparametric radar precipitation estimation in this study is comparable with the reported results by Hasan et al. (2016b). They tested their nonparametric method of radar rainfall estimation (radar reflectivity as a single predictor) in Sydney, Australia with the tropical climate and they have reported $10 \%$ improvement in RMSE compared to the traditional parametric 
Hydrol. Earth Syst. Sci. Discuss., https://doi.org/10.5194/hess-2017-662

Manuscript under review for journal Hydrol. Earth Syst. Sci.

Discussion started: 22 December 2017

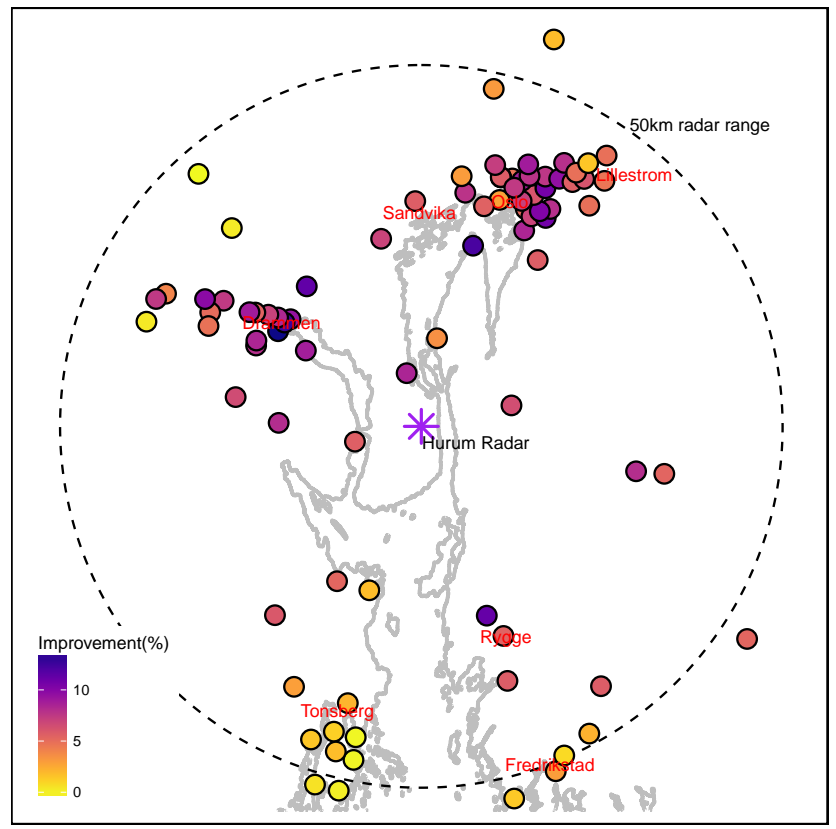

Figure 5. Percentage of improvement in RMSE, when an average partial weight of 5 neighbouring raingauges is used for radar rain rate and air temperature, compared to radar rain rate as a single predictor.

Z-R relationship. In this study, k-nearest neighbour nonparametric method with radar rain rate and air temperature as two predictors resulted in a maximum of $20 \%$ total improvement compared to the radar rain rate data which are converted by the parametric equation $\left(Z=200 R^{1.6}\right)$. The nonparametric $\mathrm{k}-\mathrm{nn}$ predictive model with radar rain rate as a single predictor improves the prediction and it is further improved by the predictive model with radar rain rate and air temperature as two covariates.

For each gauge location, we also estimated partial weights for different temperature classes. The partial weight exhibited non-stationary with air temperature. The partial weight associated with air temperature becomes zero with increasing positive temperature. For temperature above $10^{\circ} \mathrm{C}$, more than $85 \%$ of the gauge locations were estimated as having zero partial weight for air temperature. It is therefore likely that radar precipitation estimation depends on air temperature for cold climates only. The presence of hail may be the reason for a few raingauge locations are still exhibiting non-zero partial weight for air temperature above $10^{\circ} \mathrm{C}$.

Further, we estimated RMSE for the dataset above $10 \mathrm{C}$ for each gauge location using the average partial weight $(0.76 \& 0.24)$ and estimated the improvement compared to the reference model with radar rain rate as a single predictor. Nearly $70 \%$ of gauge locations still showed improvement in RMSE; however, the improvement is insignificant when the air temperature is above $10^{\circ} \mathrm{C}$. When the temperature is above $15^{\circ} \mathrm{C}$, over $45 \%$ of the locations showed an increase in RMSE. These findings suggest that a model with partial weight as a function of air temperature is required. Some gauge locations showed a clear pattern of gradual decrease in partial weight associated with air temperature from negative temperature classes to positive tempera- 
Hydrol. Earth Syst. Sci. Discuss., https://doi.org/10.5194/hess-2017-662

Manuscript under review for journal Hydrol. Earth Syst. Sci.

Discussion started: 22 December 2017

(c) Author(s) 2017. CC BY 4.0 License.

ture classes but some of the gauge locations assumed zero partial weight when the air temperature is below $10^{\circ} \mathrm{C}$. Further investigations are needed to ascertain the form of a transition for partial weight to assume zero values at higher temperatures.

\section{Summary and conclusions}

This study assessed the relevance of air temperature as an additional factor in deriving radar precipitation for cold regions and climates. The dependency of radar precipitation on the precipitation phase (snow or rain or mixture of snow and rain) was attempted. While parametric phase dependent Z-R relationships have been discussed in the literature, this is the first investigation to our knowledge that evaluates the use of temperature as a covariate and presents a procedure whereby precipitation can be estimated in cold climates.

The key findings from this study are the following:

1. Air temperature plays a significant role in determining the precipitation amount from weather radars, especially in cold climates. While this appears mostly due to the different phase of precipitation in colder temperatures (including the presence of hail), the proper use of temperature as a covariate can assist in better quantification of precipitation when no knowledge of precipitation type is available.

2. Care must be taken to use appropriate techniques to estimate precipitation when including temperature as a covariate. In the present study, use was made of a nonparametric technique which allowed for data based relationships to be formed. When equivalent data (ground rainfall especially) is not available, parametric equivalents will be needed instead. More work is needed to determine the best parametric relationship that could be adopted in such a situation.

3. A reduction of $15 \%$ in the root mean squared error was noted using the simple nonparametric approach adopted when including air temperature as an additional covariate. More than $80 \%$ of the locations data was available for exhibited clear improvements in estimates. This improvement can be expected to be significantly more if the precipitation phase can be identified using an alternative mechanism, as it is known to be the case with the identification of convective versus stratiform rainfall types in deriving radar rainfall for warmer climates (Chumchean et al., 2008).

While this study uses data for one weather radar in arriving at its conclusions, preliminary analysis suggests the problems noted here to be generic, with similar conclusions being arrived at using an alternate X-band radar for which a shorter record length is available. Given the importance of weather radars as a means of precipitation measurement, and their ability to observe in remote regions in a continuous setting, the above finding has considerable implications for ongoing operations in cold climates.

Code and data availability. Radar rain rate data used in the study are available in the Norwegian Meteorological Institute's (met.no) thredds server (http://thredds.met.no/thredds/catalog/remotesensingradaraccr/catalog.html). Precipitation observations from raingauges and raingauges' 
Hydrol. Earth Syst. Sci. Discuss., https://doi.org/10.5194/hess-2017-662

Manuscript under review for journal Hydrol. Earth Syst. Sci.

Discussion started: 22 December 2017

(c) Author(s) 2017. CC BY 4.0 License.

meta information can be obtained from met.no's web portal "eKlima" (http://eklima.met.no). Access to the web portal is available upon request. Gridded observational hourly air temperature data are available in the met.no's thredds server (http://thredds.met.no/thredds/catalog.html). NPRED programming tool, which is used for computation in the study, is available as R package and it can be downloadable from the following link as follows: http://www.hydrology.unsw.edu.au/download/software/npred

5 Competing interests. The authors declare that there are no competing interests.

Acknowledgements. The authors gratefully acknowledge Norwegian meteorological institute (met.no) for providing radar rain rate, gauge precipitation and air temperature data for this study. The authors would particularly like to thank Christoffer Artturi Elo at met.no for assisting to get the radar rain rate data. A great appreciation goes to Water Research Centre, University of New South Wales (UNSW), Sydney, Australia for hosting the first author for research practicum. The authors acknowledge the Norwegian Research Council and Norconsult for funding this research work under the Industrial Ph.D. scheme (Project No.: 255852/O30). 
Hydrol. Earth Syst. Sci. Discuss., https://doi.org/10.5194/hess-2017-662

Manuscript under review for journal Hydrol. Earth Syst. Sci.

Discussion started: 22 December 2017

(c) Author(s) 2017. CC BY 4.0 License.

\section{References}

Abdella, Y.: Quantitative estimation of precipitation from radar measurements: analysis and tool development, Ph.D. thesis, Norwegian University for Science and Technology, Trondheim, 2016.

Auer Jr, A. H.: The rain versus snow threshold temperatures, Weatherwise, 27, 67-67, 1974.

5 Battan, L. J.: Radar observation of the atmosphere, University of Chicago Press, Chicago, 1973.

Berne, A. and Krajewski, W. F.: Radar for hydrology: Unfulfilled promise or unrecognized potential?, Advances in Water Resources, 51, 357-366, 2013.

Beven, K.: Data for Rainfall-Runoff Modelling, pp. 51-82, John Wiley \& Sons, Ltd, https://doi.org/10.1002/9781119951001.ch3, 2012.

Chandrasekar, V., Keränen, R., Lim, S., and Moisseev, D.: Recent advances in classification of observations from dual polarization weather radars, Atmospheric Research, 119, 97-111, 2013.

Chumchean, S., Sharma, A., and Seed, A.: Radar rainfall error variance and its impact on radar rainfall calibration, Physics and Chemistry of the Earth, Parts A/B/C, 28, 27-39, 2003.

Chumchean, S., Sharma, A., and Seed, A.: An integrated approach to error correction for real-time radar-rainfall estimation, Journal of Atmospheric and Oceanic Technology, 23, 67-79, 2006.

Chumchean, S., Seed, A., and Sharma, A.: An operational approach for classifying storms in real-time radar rainfall estimation, Journal of hydrology, 363, 1-17, 2008.

Ciach, G. J., Krajewski, W. F., and Villarini, G.: Product-error-driven uncertainty model for probabilistic quantitative precipitation estimation with NEXRAD data, Journal of Hydrometeorology, 8, 1325-1347, 2007.

Elo, C. A.: Correcting and quantifying radar data, Tech. rep., Norwegian Meteorological Institute,Norway, 2012.

Engeland, K., Sultan Abdella, Y., and Lepioufle, J.-M.: Statistical properties of rain rates in mid Norway as seen by a vertically looking micro rain radar (MRR), in: EGU General Assembly Conference Abstracts, vol. 16, 2014.

Fassnacht, S., Kouwen, N., and Soulis, E.: Surface temperature adjustments to improve weather radar representation of multi-temporal winter precipitation accumulations, Journal of Hydrology, 253, 148-168, 2001.

Gjertsen, U. and Ødegaard, V.: The water phase of precipitation-a comparison between observed, estimated and predicted values, Atmospheric Research, 77, 218-231, 2005.

Hasan, M. M., Sharma, A., Johnson, F., Mariethoz, G., and Seed, A.: Merging radar and in situ rainfall measurements: An assessment of different combination algorithms, Water Resources Research, 52, 8384-8398, 2016a.

Hasan, M. M., Sharma, A., Mariethoz, G., Johnson, F., and Seed, A.: Improving radar rainfall estimation by merging point rainfall measurements within a model combination framework, Advances in Water Resources, 97, 205-218, $2016 \mathrm{~b}$.

30 Hong, Y. and Gourley, Jonathan, J.: Radar Hydrology: Principles, Models, and Applications, CRC Press, Boca Raton, 2015.

Joss, J., Waldvogel, A., and Collier, C.: Precipitation measurement and hydrology, in: Radar in meteorology: Battan Memorial and 40th Anniversary Radar Meteorology Conference, pp. 577-606, American Meteorological Society, 1990.

Kienzle, S. W.: A new temperature based method to separate rain and snow, Hydrological Processes, 22, 5067-5085, 2008.

Killingtveit, Å.: Water balance study in Sagelva research basin (In Norwegian: En studie av vannbalansen i Sagelva hydrologiske forskningsfelt), Ph.D. thesis, Institutt for vassbygging, Norges tekniske høgskole, Trondheim, 1976.

Kirchner, J. W.: Catchments as simple dynamical systems: Catchment characterization, rainfall-runoff modeling, and doing hydrology backward, Water Resources Research, 45, 2009. 
Hydrol. Earth Syst. Sci. Discuss., https://doi.org/10.5194/hess-2017-662

Manuscript under review for journal Hydrol. Earth Syst. Sci.

Discussion started: 22 December 2017

(c) Author(s) 2017. CC BY 4.0 License.

Koistinen, J. and Pohjola, H.: Estimation of ground-level reflectivity factor in operational weather radar networks using VPR-based correction ensembles, Journal of Applied Meteorology and Climatology, 53, 2394-2411, 2014.

Koistinen, J., Michelson, D. B., Hohti, H., and Peura, M.: Operational measurement of precipitation in cold climates, in: Weather Radar, pp.

78-114, Springer, 2004.

5 Lall, U. and Sharma, A.: A nearest neighbor bootstrap for resampling hydrologic time series, Water Resources Research, 32, 679-693, 1996.

Lussana, C., Ole, E. T., and Francesco, U.: seNorge v2.0: an observational gridded dataset of temperature for Norway, Tech. rep., Norwegian Meteorological Institute,Norway, 2016.

Marshall, J. and Gunn, K.: Measurement of snow parameters by radar, Journal of Meteorology, 9, 322-327, 1952.

Marshall, J. S. and Palmer, W. M. K.: THE DISTRIBUTION OF RAINDROPS WITH SIZE, Journal of Meteorology, 5, 165-166, 1948.

Mehrotra, R. and Sharma, A.: Conditional resampling of hydrologic time series using multiple predictor variables: A K-nearest neighbour approach, Advances in water resources, 29, 987-999, 2006.

Rohrer, M.: Determination of the transition air temperature from snow to rain and intensity of precipitation, in: WMO IASH ETH International Workshop on Precipitation Measurement, pp. 475-582, 1989.

Ryzhkov, A. and Zrnic, D.: Discrimination between rain and snow with a polarimetric radar, Journal of Applied Meteorology, 37, 1228-1240, 1998.

Saltikoff, E., Koistinen, J., and Hohti, H.: Experience of real time spatial adjustment of the ZR relation according to water phase of hydrometeors, Physics and Chemistry of the Earth, Part B: Hydrology, Oceans and Atmosphere, 25, 1017-1020, 2000.

Saltikoff, E., Lopez, P., Taskinen, A., and Pulkkinen, S.: Comparison of quantitative snowfall estimates from weather radar, rain gauges and a numerical weather prediction model, Boreal Env. Res, 20, 667-678, 2015.

Sekhon, R. and Srivastava, R.: Snow size spectra and radar reflectivity, Journal of the Atmospheric Sciences, 27, 299-307, 1970.

Sharma, A. and Mehrotra, R.: An information theoretic alternative to model a natural system using observational information alone, Water Resources Research, 50, 650-660, 2014.

Sharma, A., Mehrotra, R., Li, J., and Jha, S.: A programming tool for nonparametric system prediction using Partial Informational Correlation and Partial Weights, Environmental Modelling \& Software, 83, 271-275, 2016.

25 Silverman, B. W.: Density estimation for statistics and data analysis, vol. 26, CRC press, 1986.

Smith, P. L.: Equivalent radar reflectivity factors for snow and ice particles, Journal of Climate and Applied Meteorology, 23, 1258-1260, 1984.

Uijlenhoet, R.: Raindrop size distribution and radar reflectivity-rain rate relationships for radar hydrology, Hydrology and Earth System Sciences, 5, 615-627, 2001.

Villarini, G. and Krajewski, W. F.: Review of the different sources of uncertainty in single polarization radar-based estimates of rainfall, Surveys in Geophysics, 31, 107-129, 2010a.

Villarini, G. and Krajewski, W. F.: Sensitivity studies of the models of radar-rainfall uncertainties, Journal of Applied Meteorology and Climatology, 49, 288-309, 2010b.

Villarini, G., Serinaldi, F., and Krajewski, W. F.: Modeling radar-rainfall estimation uncertainties using parametric and non-parametric approaches, Advances in Water Resources, 31, 1674 - 1686, 2008.

Wilson, J. W. and Brandes, E. A.: Radar measurement of rainfall—A summary, Bulletin of the American Meteorological Society, 60, 10481058,1979 . 
Hydrol. Earth Syst. Sci. Discuss., https://doi.org/10.5194/hess-2017-662

Manuscript under review for journal Hydrol. Earth Syst. Sci.

Discussion started: 22 December 2017

(c) Author(s) 2017. CC BY 4.0 License.

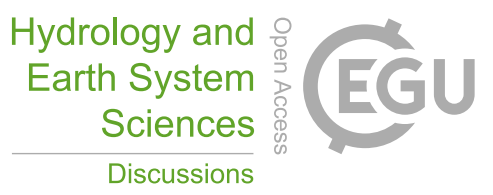

(c) (1)

Wright, D. B., Smith, J. A., Villarini, G., and Baeck, M. L.: Long-Term High-Resolution Radar Rainfall Fields for Urban Hydrology, JAWRA Journal of the American Water Resources Association, 50, 713-734, 2014. 